\title{
MODEL GENERALIZED AUTOREGRESSIVE CONDITIONAL HETEROSCEDASTICITY IN MEAN UNTUK MERAMALKAN VOLATILITAS RETURN SAHAM
}

\author{
Syarifah Zela Hafizah, Dadan Kusnandar, Shantika Martha
}

\section{INTISARI}

Volatilitas menunjukkan fluktuasi pergerakan harga saham. Semakin tinggi volatilitas maka semakin tinggi pula kemungkinan mengalami keuntungan dan kerugian. Data time series yang sering memiliki volatilitas yang tinggi adalah data keuangan. Data time series di bidang keuangan sering memiliki sifat volatility clustering atau sering disebut sebagai kasus heteroskedastisitas. Pada umumnya, pemodelan data time series harus memenuhi asumsi varian konstan (homoskedastisitas). Untuk mengatasi masalah heteroskedastisitas, model time series yang dapat digunakan adalah ARCH/GARCH. Model GARCH merupakan pengembangan dari model ARCH yang dapat digunakan untuk menggambarkan sifat dinamik volatilitas dari data. Salah satu bentuk pengembangan dari model GARCH adalah Generalized Autoregressive Conditional Heteroscedasticity in Mean (GARCH-M). Tujuan dari penelitian ini adalah untuk mengimplementasikan model GARCH-M pada peramalan volatilitas return saham. Data yang digunakan dalam penelitian ini adalah return penutupan harga saham mingguan S\&P 500 dari September 2013 sampai Juni 2019. Model terbaik yang digunakan untuk peramalan volatilitas pada return harga saham S\&P 500 adalah MA (1) GARCH $(1,1)-M$.

Kata Kunci: saham, volatilitas, GARCH-M

\section{PENDAHULUAN}

Data time series terutama data keuangan seperti indeks harga saham sering kali memiliki volatilitas yang tinggi. Volatilitas yang tinggi ditunjukkan oleh suatu tahap dimana fluktuasinya relatif tinggi, kemudian diikuti fluktuasi yang rendah dan kembali tinggi. Data demikian cenderung memiliki ratarata dan varians yang tidak konstan. Adanya volatilitas yang tinggi sulit untuk dilakukan estimasi dan prediksi pergerakan nilainya di bidang keuangan. Oleh karena itu, peramalan volatilitas memiliki pengaruh yang penting dalam pengambilan keputusan investasi. Hal itu disebabkan karena apabila volatilitas tinggi, maka ketidakpastian return saham yang diperoleh juga tinggi.

Volatilitas yang tinggi yang terdapat pada data keuangan mengakibatkan terjadinya volatility clustering atau sering disebut sebagai kasus heteroskedastisitas. Tetapi pada umumnya pemodelan data time series harus memenuhi asumsi varian konstan (homoskedastisitas). Maka dari itu, untuk mengatasi masalah heteroskedastisitas, model time series yang dapat digunakan adalah Autoregressive Conditional Heteroscedasticity (ARCH), Generalized Autoregressive Conditional Heteroskedasticity (GARCH), dan Generalized Autoregressive Conditional Heteroscedasticity in Mean (GARCH-M). GARCH-M merupakan pengembangan model GARCH. Model GARCH-M menjelaskan bahwa return suatu saham tergantung pada volatilitas. Pada model ini, didapatkan nilai risk premium yang dapat dijadikan pertimbangan dalam investasi.

Penelitian ini bertujuan untuk mengimplementasikan model GARCH-M pada peramalan volatilitas return saham. Langkah analisis yang digunakan untuk mengaplikasikan GARCH-M untuk peramalan volatilitas return saham, yang pertama adalah menghitung nilai return harga saham. Kemudian menguji stasioneritas data return dengan uji ADF, jika data stasioner dilanjutkan dengan mengidentifikasi model mean dengan model ARIMA. Setelah didapat model ARIMA, diuji heteroskedastisitasnya. Apabila terdapat heteroskedastisitas, dilanjutkan dengan mengidentifikasi model varians dengan model GARCH-M. Terakhir melakukan peramalan volatilitas dengan GARCHM. 


\section{ANALISIS TIME SERIES}

Metode yang digunakan untuk menentukan model yang sesuai pada data time series adalah metode Box-Jenkins. Metode tersebut dikenal dengan model Autoregressive Moving Average (ARMA) untuk data stasioner dan Autoregressive Integrated Moving Average (ARIMA) untuk data non stasioner. Model ARMA merupakan gabungan dari metode AR (Autoregressive) dan MA (Moving Average).

Autoregressive adalah suatu bentuk regresi tetapi bukan yang menghubungkan variabel tak bebas, melainkan menghubungkan nilai-nilai sebelumnya pada time lag (selang waktu) yang bermacammacam. Model Autoregressive dengan orde $p$ dinotasikan dengan AR $(p)$. Pada model AR, $X_{t}$ dipengaruhi oleh $p$ amatan yang lalu dan dapat dituliskan sebagai $[1,2]$ :

$$
X_{t}=\omega_{1} X_{t-1}+\omega_{2} X_{t-2}+\ldots+\omega_{p} X_{t-p}+\varepsilon_{t}
$$

Moving Average dengan orde $q$ dinotasikan dengan MA (q). Moving Average merupakan proses dimana $X_{t}$ dihasilkan dari forecast error beberapa periode sebelumnya. Model MA dapat didefinisikan sebagai $[1,2]$ :

$$
X_{t}=\varepsilon_{t}+\theta_{1} \varepsilon_{t-1}+\theta_{2} \varepsilon_{t-2}+\ldots+\theta_{q} \varepsilon_{t-q}
$$

Model Autoregressive Moving Average (ARMA) merupakan suatu kombinasi dari model AR dan MA. Secara umum model ARMA $(p, q)$ adalah sebagai berikut $[1,2]$ :

$$
X_{t}=\sum_{i=1}^{p} \omega_{i} X_{t-\mathrm{i}}+\sum_{j=1}^{q} \theta_{j} \varepsilon_{t-j}+\varepsilon_{t}
$$

Pada umumnya pemodelan data time series harus memenuhi asumsi varians error yang konstan (homoskedastisitas). Namun data time series pada sektor keuangan sangat tinggi volatilitasnya dan sering terjadi heteroskedastisitas. Untuk mengatasi masalah heteroskedastisitas, maka digunakan model ARCH. Model Autoregressive Conditional Heteroscedastic (ARCH) adalah model yang digunakan untuk mengatasi heteroskedastisitas dalam time series. Bentuk umum model ARCH $(p)$ [3]:

$$
\sigma_{t}^{2}=a_{0}+a_{1} \varepsilon_{t-1}^{2}+a_{2} \varepsilon_{t-2}^{2}+\ldots+a_{p} \varepsilon_{t-p}^{2}
$$

Bollerslev (1986) mengembangkan model ARCH. Model tersebut disebut dengan Generalized Autoregressive Conditional Heteroscedasticity (GARCH). Model GARCH adalah salah satu model time series yang dapat digunakan untuk menggambarkan sifat dinamik volatilitas dari data. Penerapan model tersebut pada data historis akan membangkitkan perkiraan statistik volatilitas pada masa lalu, dimana dari data waktu ke waktu tersedia. Hal itu juga akan menimbulkan peramalan terhadap volatilitas dari sekarang sampai suatu titik di masa yang akan datang. Bentuk umum model GARCH $(p, q)[4]:$

$$
\sigma_{t}^{2}=a_{0}+a_{1} \varepsilon_{t-1}^{2}+\ldots+a_{p} \varepsilon_{t-p}^{2}+\beta_{1} \sigma_{t-1}^{2}+\ldots+\beta_{q} \sigma_{t-q}^{2}
$$

Salah satu pengembangan GARCH adalah GARCH in mean atau disingkat GARCH-M. Model GARCH-M terdapat varians atau standar deviasi di dalam persamaan mean. Hal ini dilakukan pada kasus-kasus tertentu, misalnya pada kondisi seorang investor yang menyenangi risiko. Investor yang ingin mendapatkan risk premium dari saham yang memiliki risiko tinggi, dapat menggunakan metode ini.

Model GARCH $(p, q)$-M dengan varians dapat dinyatakan dengan persamaan sebagai berikut [5]: Mean Equation:

$$
y_{t}=\gamma x_{t}+c \sigma_{t}^{2}+\varepsilon_{t}
$$


Variance Equation:

$$
\sigma_{t}^{2}=\alpha_{0}+\sum_{i=1}^{p} \alpha_{i} \varepsilon_{t-i}^{2}+\sum_{j=1}^{q} \beta_{j} \sigma_{t-j}^{2}
$$

\section{HASIL DAN PEMBAHASAN}

Data yang digunakan dalam penelitian ini adalah data sekunder yaitu harga indeks saham S\&P 500 mingguan jangka waktu September 2013 sampai Juni 2019. Untuk mengetahui pergerakan harga saham tersebut, diperoleh grafik harga saham adalah sebagai berikut:

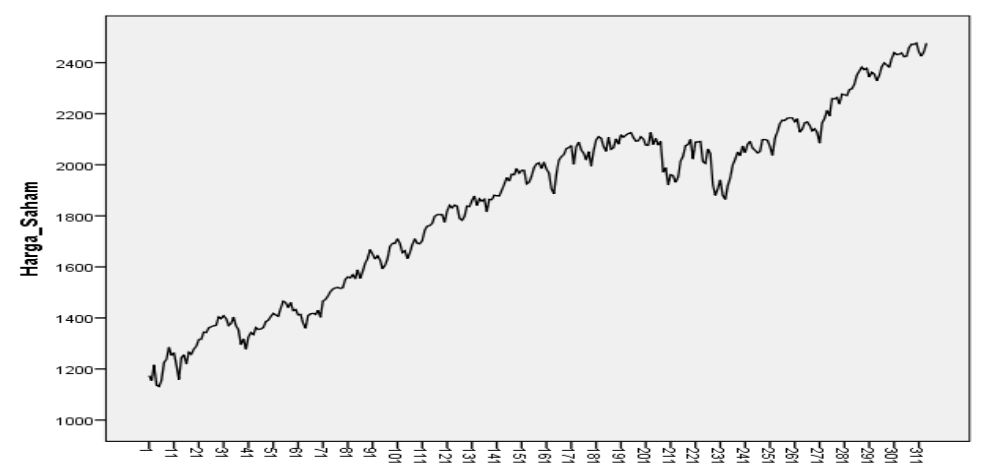

Gambar 1 Grafik Data Harga Saham S\&P 500

Gambar 1 menunjukkan bahwa data harga saham S\&P 500 mengalami trend yang naik. Terlihat adanya volatilitas yang sangat fluktuatif dari data, sehingga dapat disimpulkan secara subyektif bahwa terdapat volatilitas pada data. Karakteristik data yang dianalisis adalah data return harga saham penutupan S\&P 500 .

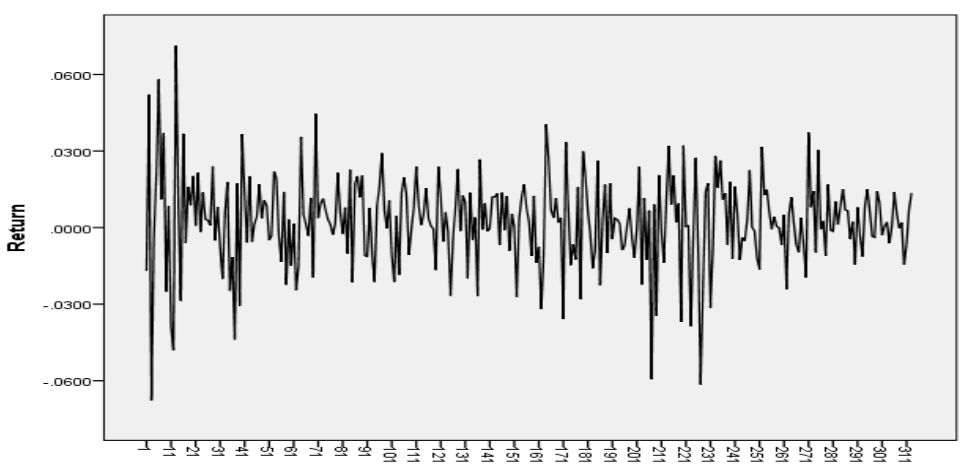

Gambar 2 Grafik Data Return Harga Saham S\&P 500

Pada Gambar 2 terlihat bahwa plot return saham S\&P 500 telah stasioner. Hal ini terlihat dari ratarata deret pengamatan di sepanjang waktu yang selalu konstan (berfluktuasi di sekitar nilai tengah).

Uji stasioner pada data return juga dilakukan dengan uji Augmented Dickey Fuller (ADF). Adapun hipotesis uji ADF yang digunakan adalah sebagai berikut:

$H_{0}$ : Data return tidak stasioner

$H_{1}$ : Data return stasioner

Jika nilai probabilitas kurang dari nilai $\alpha=0,05$ maka $H_{o}$ ditolak. 
Tabel 1 Uji Augmented Dickey Fuller (ADF)

\begin{tabular}{ccc}
\hline & $t$-Statistic & Prob \\
\hline ADF Test & $-20,35264$ & 0,0000 \\
\hline Test critical value & $1 \%$ level & $-3,451146$ \\
& $5 \%$ level & $-2,870591$ \\
& $10 \%$ level & $-2,571663$ \\
\hline
\end{tabular}

Berdasarkan Tabel 1 nilai probabilitas uji ADF kurang dari $\alpha$ yang berarti $H_{0}$ ditolak, artinya data return telah stasioner. Hasil uji ADF mendukung kesimpulan bahwa data dapat dimodelkan dengan $\operatorname{ARMA}(p, q)$.

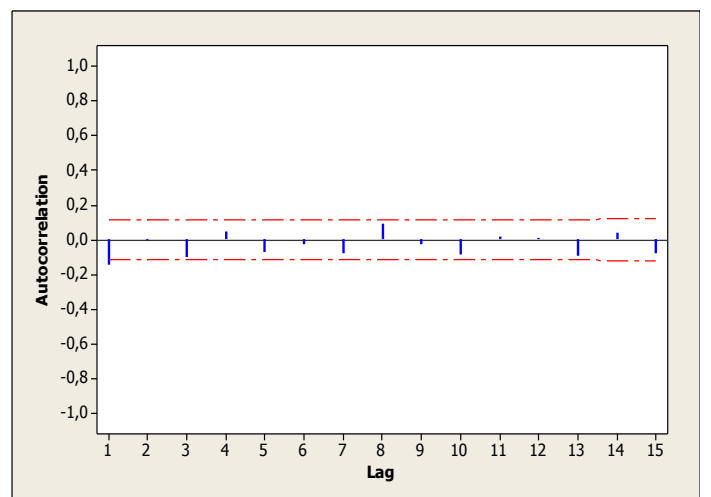

Gambar 3 Plot ACF Data Return

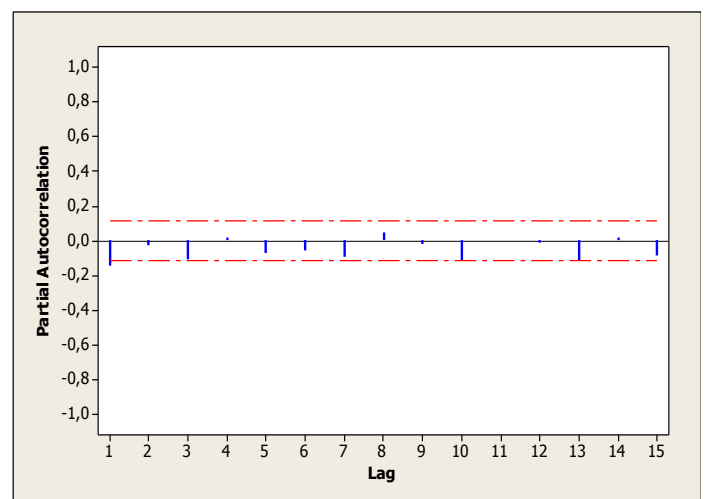

Gambar 4 Plot PACF Data Return

Berdasarkan Gambar 3 dan Gambar 4 model yang teridentifikasi adalah AR (1) dan MA (1) pada data return harga saham. Model kombinasi yang didapatkan yaitu AR (1), MA (1), dan ARMA $(1,1)$.

Adapun hipotesis uji yang digunakan untuk menguji signifikansi parameter model adalah sebagai berikut:

$H_{0}$ : Paramater tidak signifikan dalam model

$H_{1}$ : Parameter signifikan dalam model

Jika nilai probabilitas kurang dari $\alpha=0,05$ maka $H_{0}$ ditolak.

Tabel 2 Estimasi dan Uji Signifikansi Paramater

\begin{tabular}{ccccc}
\hline Model & Parameter & Koefisien & Prob & Keputusan \\
\hline AR (1) & $\omega_{1}$ & $-0,142739$ & 0,0011 & Signifikan \\
MA (1) & $\theta_{1}$ & $-0,153824$ & 0,0004 & Signifikan \\
ARMA (1,1) & $\omega_{1}$ & 0,734785 & 0,0000 & Signifikan \\
& $\theta_{1}$ & $-0,863848$ & 0,0000 & Signifikan \\
\hline
\end{tabular}

Berdasarkan Tabel 2 semua nilai probabilitas kurang dari $\alpha$ yang berarti $H_{o}$ ditolak, artinya parameter signifikan dalam model.

Selanjutnya dilakukan verifikasi model ARMA yang dilakukan untuk mengetahui residual apakah mengandung autokorelasi atau white noise. Adapun hipotesis uji yang digunakan adalah sebagai berikut:

$H_{0}$ : Residual white noise

$H_{1}$ : Residual tidak white noise 
Jika nilai probabilitas kurang dari $\alpha(0,05)$ maka $H_{0}$ ditolak.

\begin{tabular}{|c|c|c|c|c|c|}
\hline Autocorrelation & Partial Correlation & $A C$ & PAC & Q-Stat & Prob \\
\hline 111 & 111 & $1-0.004$ & -0.004 & 0.0041 & \\
\hline 10 & 101 & $2-0.041$ & -0.041 & 0.5336 & 0.465 \\
\hline d & di & $3-0.095$ & -0.095 & 3.3937 & 0.183 \\
\hline 1 1 1 & 10 1 ו & $\begin{array}{ll}4 & 0.028\end{array}$ & 0.025 & 3.6393 & 0.303 \\
\hline 101 & 101 & $5-0.071$ & -0.079 & 5.2338 & 0.264 \\
\hline 101 & 10 & $6-0.051$ & -0.059 & 6.0550 & 0.301 \\
\hline 101 & 1 & $7-0.072$ & -0.076 & 7.7188 & 0.259 \\
\hline 19 & 1 p & $\begin{array}{ll}8 & 0.078\end{array}$ & 0.058 & 9.6971 & 0.206 \\
\hline 14 & 1. & $\begin{array}{ll}9 & -0.028\end{array}$ & -0.042 & 9.9466 & 0.269 \\
\hline d & di & $10-0.090$ & -0.105 & 12.586 & 0.182 \\
\hline 111 & 111 & $\begin{array}{ll}11 & 0.012\end{array}$ & 0.016 & 12.630 & 0.245 \\
\hline 11 & 1. 1 & $12 \quad 0.004$ & -0.030 & 12.635 & 0.318 \\
\hline d & ¿1 & $13 \quad-0.088$ & -0.109 & 15.185 & 0.231 \\
\hline 111 & 111 & $\begin{array}{ll}14 & 0.021\end{array}$ & 0.021 & 15.327 & 0.287 \\
\hline 1다 1 & d 1 & $\mid$\begin{tabular}{|ll}
15 & -0.062
\end{tabular} & -0.087 & 16.611 & 0.278 \\
\hline
\end{tabular}

Gambar 5 Uji Autokorelasi Residual AR (1)

\begin{tabular}{|c|c|c|c|c|c|c|}
\hline Autocorrelation & Partial Correlation & & $A C$ & PAC & Q-Stat & Prob \\
\hline 111 & $1 / 1$ & 1 & 0.005 & 0.005 & 0.0078 & \\
\hline 11 & 11 & 2 & -0.019 & -0.020 & 0.1281 & 0.720 \\
\hline d & di & & -0.096 & -0.096 & 3.0806 & 0.214 \\
\hline 1) 1 & 1 1 & 4 & 0.024 & 0.025 & 3.2719 & 0.352 \\
\hline 1 & 101 & 5 & -0.075 & -0.079 & 5.0518 & 0.282 \\
\hline 1 & 10 & & -0.050 & -0.058 & 5.8552 & 0.321 \\
\hline 10 & 101 & 7 & -0.074 & -0.073 & 7.6166 & 0.268 \\
\hline ין & ין ו & 8 & 0.074 & 0.057 & 9.3906 & 0.226 \\
\hline 1 & 101 & 9 & -0.029 & -0.042 & 9.6710 & 0.289 \\
\hline d & ¿1 & 10 & -0.089 & -0.106 & 12.231 & 0.201 \\
\hline 11 & 111 & 11 & 0.008 & 0.015 & 12.253 & 0.268 \\
\hline 11 & 10 & 12 & 0.002 & -0.028 & 12.254 & 0.345 \\
\hline d & d & 13 & -0.089 & -0.110 & 14.865 & 0.249 \\
\hline 111 & 111 & 14 & 0.020 & 0.022 & 15.000 & 0.307 \\
\hline 1 & di & 15 & -0.064 & -0.085 & 16.357 & 0.292 \\
\hline
\end{tabular}

Gambar 6 Uji Autokorelasi Residual MA (1)

\begin{tabular}{|c|c|c|c|c|c|c|}
\hline Autocorrelation & Partial Correlation & & $A C$ & PAC & Q-Stat & Prob \\
\hline 101 & 1 & & $1-0.039$ & -0.039 & 0.4732 & \\
\hline ין י מי & 1 & & 20.062 & 0.060 & 1.6836 & \\
\hline $1 \sqrt{1}$ & $1 \sqrt{1}$ & & $3-0.038$ & -0.033 & 2.1363 & 0.144 \\
\hline 19 & 19 & & $4 \quad 0.081$ & 0.075 & 4.2296 & 0.121 \\
\hline $1 \sqrt{1}$ & $1 \sqrt{1}$ & & $5-0.039$ & -0.030 & 4.7241 & 0.193 \\
\hline 11 & 111 & & -0.010 & -0.023 & 4.7552 & 0.313 \\
\hline 10 & 10 & & -0.060 & -0.053 & 5.9195 & 0.314 \\
\hline 10 & 19 & & 3 0.087 & 0.078 & 8.3619 & 0.213 \\
\hline 11 & 1 & & -0.023 & -0.008 & 8.5299 & 0.288 \\
\hline 101 & d & 10 & -0.080 & -0.094 & 10.596 & 0.226 \\
\hline 1111 & 111 & 11 & 10.015 & 0.025 & 10.672 & 0.299 \\
\hline 11 & 11 & 12 & 20.008 & 0.003 & 10.693 & 0.382 \\
\hline d 1 & d & 13 & $3-0.088$ & -0.092 & 13.220 & 0.279 \\
\hline 1 & ין י י & 14 & $4 \quad 0.036$ & 0.046 & 13.657 & 0.323 \\
\hline प1 & 14 & 15 & $5-0.066$ & -0.054 & 15.086 & 0.302 \\
\hline
\end{tabular}

Gambar 7 Uji Autokorelasi Residual ARMA $(1,1)$

Diketahui nilai probabilitas lebih dari $\alpha$ yang berarti $H_{0}$ diterima, artinya residual white noise.

Selanjutnya dilakukan pemilihan model terbaik model ARMA dengan melihat nilai SIC dan BIC terkecil.

Tabel 3 Pemilihan Model Terbaik

\begin{tabular}{ccc}
\hline Model & SIC & BIC \\
\hline AR (1) & $-5,2004$ & $-8,050$ \\
MA (1) & $\mathbf{- 5 , 2 0 1 7}$ & $\mathbf{- 8 , 0 5 2}$ \\
ARMA $(1,1)$ & $-5,1971$ & $-8,042$ \\
\hline
\end{tabular}

Berdasarkan Tabel 3 maka diperoleh model terbaik yaitu model MA (1) yang memiliki nilai SIC dan BIC terkecil.

Selanjutnya dilakukan uji heteroskedastisitas atau menguji apakah model mengandung efek heteroskedastisitas atau tidak. Adapun hipotesis uji yang digunakan adalah sebagai berikut:

$$
\begin{aligned}
& H_{0}: \alpha_{1}=\alpha_{2}=\ldots=\alpha_{m}=0 \\
& H_{1}: \alpha_{1}=\alpha_{2}=\ldots=\alpha_{m} \neq 0
\end{aligned}
$$

Jika nilai probabilitas kurang dari $\alpha=0,05$ maka $H_{o}$ ditolak.

Tabel 4 Uji Heteroskedastisitas MA (1)

\begin{tabular}{llll}
\hline F-statistic & 15,68244 & Prob. F $(1,310)$ & 0,0001 \\
Obs*R-Squared & 15,02360 & Prob. Chi-Square (1) & 0,0001 \\
\hline
\end{tabular}


Berdasarkan Tabel 4 nilai probabilitas kurang dari $\alpha(0,05)$ yang berarti $H_{0}$ ditolak. Artinya terdapat heteroskedastisitas pada residual atau mengandung efek ARCH/GARCH.

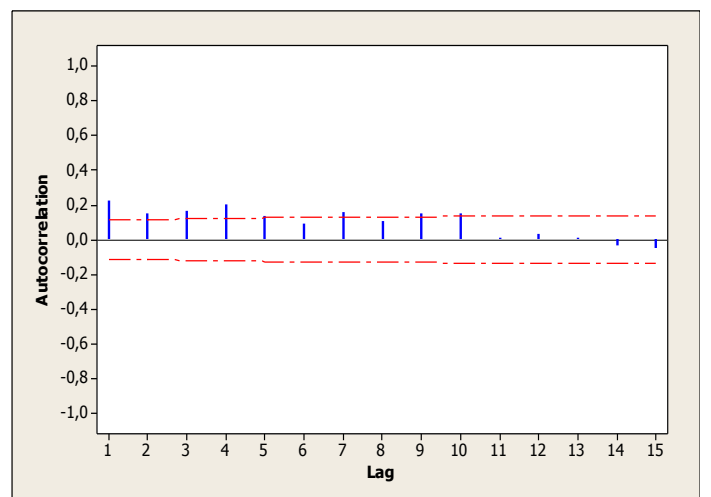

Gambar 8 Plot ACF Residual Kuadrat

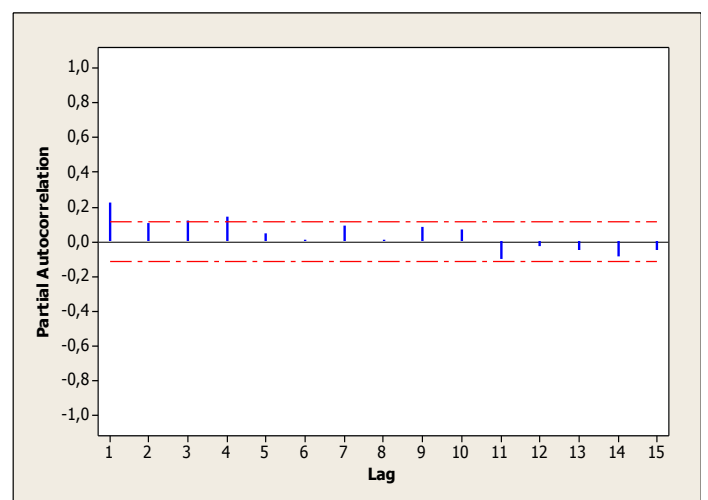

Gambar 9 Plot PACF Residual Kuadrat

Model MA (1) selanjutnya dapat dimodelkan ke dalam model GARCH-M dan dibatasi hanya sampai lag kedua, yaitu MA (1) GARCH (1,1)-M; MA (1) GARCH (1,2)-M; MA (1) GARCH $(2,1)$ M; MA (1) GARCH (2,2)-M.

Adapun hipotesis uji yang digunakan untuk menguji signifikansi parameter model adalah sebagai berikut:

$H_{0}$ : Paramater tidak signifikan dalam model

$H_{1}$ : Parameter signifikan dalam model

Jika nilai probabilitas kurang dari $\alpha$ maka $H_{0}$ ditolak. Setelah dilakukan estimasi dan uji signifikansi terhadap semua model, didapat model yang memiliki parameter yang signifikan pada semua komponennya adalah model MA (1) GARCH $(1,1)$-M seperti pada Tabel 5.

Tabel 5 Estimasi dan Uji Signifikansi MA (1) GARCH (1,1)-M

\begin{tabular}{ccccl}
\hline Model & Parameter & Koefisien & Prob. & Keputusan \\
\hline MA (1) GARCH (1,1)-M & $c$ & 12,77171 & 0,0333 & Signifikan \\
& $\theta_{1}$ & $-0,134909$ & 0,0349 & Signifikan \\
$\alpha_{0}$ & 0,0000287 & 0,0374 & Signifikan \\
& $\alpha_{1}$ & 0,127150 & 0,0244 & Signifikan \\
& $\beta_{1}$ & 0,761201 & 0,0000 & Signifikan
\end{tabular}

Selanjutnya dilakukan verifikasi model GARCH $(p, q)$-M yang dilakukan untuk mengetahui apakah residual mengandung autokorelasi atau white noise. Adapun hipotesis uji yang digunakan adalah sebagai berikut:

$H_{0}$ : Residual white noise

$H_{1}$ : Residual tidak white noise

Jika nilai probabilitas kurang dari $\alpha(0,05)$ maka $H_{o}$ ditolak. Nilai probabilitas pada Tabel 5 lebih dari $\alpha$ yang berarti $H_{0}$ diterima, artinya residual white noise.

Selanjutnya dilakukan kembali uji heteroskedastisitas model MA (1) GARCH (1,1)-M.

Tabel 6 Uji Heteroskedastisitas MA (1) GARCH (1,1)-M

\begin{tabular}{llll}
\hline F-statistic & 0,450326 & Prob. F $(1,400)$ & 0,5026 \\
Obs*R-Squared & 0,452069 & Prob. Chi-Square (1) & 0,5014 \\
\hline
\end{tabular}


Berdasarkan Tabel 6, nilai probabilitas lebih dari $\alpha$ yang berarti $H_{0}$ diterima, artinya tidak terdapat heteroskedastisitas pada residual.

Langkah terakhir yang dilakukan adalah meramalkan volatilitas untuk beberapa periode selanjutnya dengan menggunakan model yang sesuai yaitu MA (1) GARCH $(1,1)-\mathrm{M}$

dengan

$$
\hat{y}_{t}=-0,134909 \varepsilon_{t-1}+12,77171 \sigma_{t}^{2}
$$

$$
\sigma_{t}^{2}=0,0000287+0,127150 \varepsilon_{t-1}^{2}+0,761201 \sigma_{t-1}^{2}
$$

Hasil peramalan volatilitas pada return harga saham S\&P 500 menggunakan model MA (1) GARCH (1,1)-M untuk lima minggu ke depan adalah sebagai berikut:

Tabel 7 Hasil Peramalan Volatilitas

\begin{tabular}{cc}
\hline Minggu ke- & Peramalan Volatilitas \\
\hline 1 & 0,01305 \\
2 & 0,01342 \\
3 & 0,01373 \\
4 & 0,01401 \\
5 & 0,01425 \\
\hline
\end{tabular}

\section{KESIMPULAN}

Penerapan pemodelan GARCH-M pada studi kasus harga return saham mingguan S\&P 500 diperoleh model terbaik MA (1) GARCH (1,1)-M. Model yang digunakan untuk meramalkan volatilitas return saham adalah:

$$
\hat{y}_{t}=-0,134909 \varepsilon_{t-1}+12,77171 \sigma_{t}^{2}
$$

dengan

$$
\sigma_{t}^{2}=0,0000287+0,127150 \varepsilon_{t-1}^{2}+0,761201 \sigma_{t-1}^{2}
$$

Dengan model tersebut diperoleh estimasi volatilitas selama lima minggu kedepan. Nilai ramalan volatilitas yang dihasilkan berkisar 0,01305 sampai 0,01425. Nilai tersebut memiliki selisih yang relatif kecil, maka dapat dikatakan volatilitas tergolong rendah, sehingga nilai return dan risikonya juga rendah.

\section{DAFTAR PUSTAKA}

[1]. Lo, M.S. Generalized Autoregressive Conditional Heteroscedastic Time Series Model. Simon Fraser University. 2003.

[2]. Wei, W.W.S. Time Series Analysis, Univariate and Multivariate Methods. Redwood City: Addison-Wesley Publishing Company, Inc. 2006.

[3]. Desvina, A. P dan Nadya, R. Penerapan metode ARCH/GARCH dalam peramalan Indeks Harga Saham Sektoral. Jurnal Sains Matematika dan Statistika. 2016. 2 (1): 1-10.

[4]. Hartati dan Imelda, S. Aplikasi GARCH dalam Mengatasi Volatilitas pada Data Keuangan. Jurnal Matematika. 2017.7 (2): 107-118.

[5]. Ekananda, M. Analisis Data Time Series. Jakarta: Mitra Wacana Media. 2014. 
SYARIFAH ZELA HAFIZAH $\quad$ : J Jurusan Matematika, FMIPA UNTAN, Pontianak

DADAN KUSNANDAR

SHANTIKA MARTHA syarifahzela@gmail.com

: $\quad$ Jurusan Matematika, FMIPA UNTAN, Pontianak dkusnand@untan.ac.id

: Jurusan Matematika, FMIPA UNTAN, Pontianak shantika.martha@math.untan.ac.id 